\title{
IL-3 can not replace GM-CSF in inducing human monocytes to differentiate into Langerhans cells
}

\author{
TETSUNORI SHIBASAKI ${ }^{1}$, NAOYUKI KATAYAMA $^{1}$, KOHSHI OHISHI $^{1}$, ATSUSHI FUJIEDA $^{1}$, \\ FUMIHIKO MONMA ${ }^{1}$, KAZUHIRO NISHII ${ }^{1}$, MASAHIRO MASUYA ${ }^{2}$ and HIROSHI SHIKU ${ }^{1}$ \\ ${ }^{1}$ Department of Hematology and Oncology, Mie University Graduate School of Medicine; \\ ${ }^{2}$ Blood Transfusion Service, Mie University Hospital, Tsu, Mie 514-8507, Japan
}

Received October 27, 2006; Accepted December 21, 2006

\begin{abstract}
Receptors for granulocyte-macrophage colonystimulating factor (GM-CSF) and interleukin-3 (IL-3) share a common $\beta$ subunit. We recently reported that GM-CSF acts in concert with transforming growth factor- $\beta 1$ (TGF- $\beta 1$ ) and Notch ligand Delta-1 (Delta-1) to promote the differentiation of human blood monocytes into Langerhans cells. In the present study, we examined whether IL-3, in place of GMCSF, can induce the development of Langerhans cells from blood monocytes in the presence of TGF- $\beta 1$ and Delta-1, because the IL-3 receptor $\alpha$ chain was substantially expressed on monocytes. However, the generation of Langerhans cells was not obtained by the combination of IL-3, TGF- 11 and Delta-1, even though GM-CSF and IL-3 exhibited a similar effect with respect to the differentiation of monocytes into macrophages and dendritic cells. The addition of GM-CSF to the culture supplemented with IL-3, TGF- 31 and Delta-1 restored the differentiation of monocytes toward Langerhans cells. A microarray analysis revealed that a number of genes including Langerhans cell markers, E-cadherin and Langerin, were specifically expressed in cells from GM-CSF-containing cultures but not in those from IL-3-containing cultures. These data suggest that IL-3 can not replace GM-CSF to induce the differentiation of human monocytes into Langerhans cells in culture.
\end{abstract}

\section{Introduction}

The differentiation and proliferation of hematopoietic cells are at least in part regulated by hematopoietic growth factors that serve a variety of functions by interacting with their receptors

Correspondence to: Dr Naoyuki Katayama, Department of Hematology and Oncology, Mie University Graduate School of Medicine, 2-174 Edobashi, Tsu, Mie 514-8507, Japan

E-mail: n-kata@clin.medic.mie-u.ac.jp

Key words: granulocyte-macrophage colony-stimulating factor, interleukin-3, Langerhans cells, monocytes, differentiation
(1-4). Among these growth factors, granulocyte-macrophage colony-stimulating factor (GM-CSF), interleukin-3 (IL-3) and IL-5 display similar biologic activities and cross-competition as well as distinct activities, depending on the type of target cells (5). Receptors for GM-CSF, IL-3 and IL-5 are heterodimers composed of two subunits: a unique $\alpha$ chain and a common $\beta($ ( ) ) chain. The $\alpha$ chain binds to each cytokine with a low affinity. The binding of a cytokine to its $\alpha$ chain leads to cross-linking with the Bc chain, thereby forming the high-affinity receptors. The association between the $\alpha$ and Bc chains is required for signal transduction. As these subunits lack intrinsic tyrosine kinase domains, tyrosine kinases that are closely associated with the receptors seem to be activated for the intracellular transmission of their signals. Overlapping biologic activities result from the signal events mediated through the ßc receptor component, whereas the cytokinespecific responses elicited by these cytokines are dependent on the distribution of their specific $\alpha$ chain receptor component.

Monocytes are a population of leukocytes that originate in the bone marrow and enter the peripheral blood as nondividing cells (6). Subsequently, they migrate from the bloodstream into various peripheral tissues in response to various stimuli. During this process, they undergo terminal differentiation to become macrophages. Both $\alpha$ chain receptor components for GM-CSF and IL-3 are expressed in human monocytes (7). Monocytes differentiate into macrophages upon in vitro culture with GM-CSF or IL-3 $(5,8)$. GM-CSF in combination with IL-4 promotes the differentiation of peripheral blood monocytes into immature dendritic cells (DCs) (9-11). The culturing of monocytes with IL-3 and IL-4 gives rise to cells with the morphologic, phenotypic, and immunostimulatory features of monocyte-derived DCs (12). Since biologic activities of GM-CSF on human monocytes overlap substantially with those of IL-3, it is likely that signal events mediated through the $\mathrm{Bc}$ chain are responsible for the actions of GM-CSF and IL-3 on monocytes.

Recently, we found that GM-CSF, transforming growth factor-31 (TGF-B1), and Notch ligand Delta-1, all of which are synthesized in the milieu of the skin, induce the differentiation of human blood monocytes into Langerhans cells (13). As previous studies have demonstrated similar activities of GM-CSF and IL-3 on human blood monocytes $(5,12)$, we investigated whether IL-3 can replace GM-CSF 
to generate Langerhans cells from blood monocytes. Our findings indicate that GM-CSF is indispensable for the development of Langerhans cells from monocytes in the presence of TGF-ß1 and Notch ligand Delta-1.

\section{Materials and methods}

Cell preparation. Peripheral blood was obtained from healthy adult Japanese donors who all gave their written informed consent. Peripheral blood mononuclear cells were separated by Ficoll-Hypaque density gradient centrifugation, washed with $\mathrm{Ca}^{2+}-, \mathrm{Mg}^{2+}$-free phosphate-buffered saline (PBS), and then suspended in PBS with $0.1 \%$ bovine serum albumin (BSA) (Sigma, St. Louis, MO, USA). CD14+ cells were positively separated from peripheral blood mononuclear cell fractions, using CD14 immunomagnetic beads and magnetic separation columns (MACS; Miltenyi Biotec, Auburn, CA, USA) according to the manufacturer's instructions. When the purity of $\mathrm{CD} 14^{+}$cells was $<95 \%$, as determined by a FACSCalibur flow cytometer (Becton Dickinson, San Jose, CA, USA), this passage through the magnetic separation column was repeated until the purity reached $>95 \%$. When stained with myeloperoxidase (MPO) staining kits and double specific (naphthol AS-D chloroacetate esterase)/non-specific ( $\alpha$-naphthyl butyrate esterase) esterase staining kits, the CD14+ cells were positive for MPO and non-specific esterase, but negative for specific esterase.

Cytokines and reagents. The immobilized extracellular domain of Delta-1 was used as Notch ligand Delta-1. The extracellular domain of Delta-1 with 6 myc-tags (Delta- $1^{\text {ext-myc }}$ ) was prepared, as previously described $(14,15)$. Delta- $1^{\text {ext-myc }}(1 \mu \mathrm{g} / \mathrm{ml})$ was immobilized on the 24-well tissue culture plates (Nunc, Roskilde, Denmark) that were incubated with $\left.\mathrm{F}(\mathrm{ab})_{2}\right)_{2}$ fragments of a mouse anti-myc antibody, 9E10, at the concentration of $5 \mu \mathrm{g} / \mathrm{ml}$ for $30 \mathrm{~min}$ at $37^{\circ} \mathrm{C}$. The culture plates were washed with $0.1 \%$ BSA PBS. Delta- $1^{\text {ext-myc }}$ and 9E10 were gifts from Dr I.D. Bernstein (Fred Hutchinson Cancer Research Center, Seattle, WA, USA). Recombinant human GM-CSF and IL-3 were gifts from Kirin Brewery (Tokyo, Japan). Recombinant IL-4 was purchased from Genzyme (Cambridge, MA, USA). Recombinant human TGF- 31 was purchased from R\&D Systems (Minneapolis, MN, USA). The concentrations of the cytokines used in this study were as follows: GM-CSF, 10 ng/ml; IL-3, 10 ng/ml; IL-4, 10 ng/ml; TGF-ß1, 10 ng/ml.

Culture. RPMI-1640 culture medium (Nissui Pharmaceutical, Tokyo, Japan) was supplemented with $2 \mathrm{mM}$ L-glutamine, $50 \mathrm{U} / \mathrm{ml}$ penicillin, $50 \mu \mathrm{g} / \mathrm{ml}$ streptomycin and $10 \%$ fetal bovine serum (FBS) (HyClone Laboratories, Logan, UT, USA). CD14+ cells $\left(5 \times 10^{5} / \mathrm{ml}\right)$ were seeded in the 24 -well tissue culture plates with designated combinations of cytokines for 7 days. Half of the culture medium was removed and replaced with fresh medium with cytokines on day 3 or 4 .

Flow cytometry. Flow cytometry was performed using a FACSCalibur flow cytometer. The data were analyzed using CellQuest software (BD Biosciences, San Jose, CA, USA). For membrane staining, freshly isolated and cultured cells were stained with monoclonal antibodies (mAbs) for $30 \mathrm{~min}$ on ice and then they were washed three times with $0.1 \%$ BSA PBS. The cells were resuspended in $0.1 \%$ BSA PBS containing $1 \mu \mathrm{g} / \mathrm{ml}$ propidium iodide and incubated in the dark for $10 \mathrm{~min}$ at room temperature, in order to exclude dead cells from the analysis. An intracellular molecule was stained using the Cytofix/Cytoperm kit (BD Biosciences Pharmingen, San Diego, CA, USA). The cells were fixed for $20 \mathrm{~min}$ at $4^{\circ} \mathrm{C}$ with formaldehyde-based fixation medium. After washing twice with PBS, the cells were resuspended in the permeabilization buffer and stained with $\mathrm{mAb}$. PBS containing $\mathrm{Ca}^{2+}$ was used instead of PBS for staining of E-cadherin. The following murine mAbs were used: fluorescein isothiocyanate (FITC)-conjugated anti-GM-CSFR $\alpha$ (CD116) (antiGM-CSFR $\alpha$-FITC) and phycoerythrin (PE)-conjugated anti-IL-3R $\alpha$ (CD123) (anti-IL-3R $\alpha$-PE) (Pharmingen); antiCD1a-PE, anti-Langerin (CD207)-PE, unconjugated antiE-cadherin, and anti-CD40-PE (Immunotech, Marseille, France); anti-HLA-ABC-PE and anti-MPO-FITC (Dako, Glostrup, Denmark); anti-CD16-PE, anti-CD11c-PE, antiCD14-PE, anti-HLA-DR-PE, anti-CD80-PE and anti-CD54PE (BD Biosciences); anti-macrophage-colony stimulating factor receptor (M-CSFR; CD115)-FITC (Oncogene Research, Boston, MA, USA); anti-CD86-PE and anti-DCSIGN (CD209)-PE (BD Biosciences Pharmingen); antiCCR6-FITC (R\&D Systems). An anti-cutaneous lymphocyteassociated antigen (CLA)-FITC rat mAb (BD Biosciences Pharmingen) was also used. Mouse IgG1-PE, mouse IgG2bPE, rat IgM-FITC and rat anti-mouse IgG1-FITC were purchased from BD Biosciences Pharmingen. Purified mouse IgG1 (R\&D Systems), mouse IgM-FITC, mouse IgG2a-PE (Pharmingen) or mouse IgG2b-FITC (Beckman Coulter, Hialeah, FL, USA) served as an isotype control.

Microarray. Microarray assay was carried out as described with some modifications $(16,17)$. Double-stranded cDNA was synthesized from total RNA extracted from each sample by the acid guanidinium method, using the One-Cycle cDNA Synthesis kit (Affymetrix, Santa Clara, CA, USA). Biotinlabeled cRNA was prepared from each cDNA by 3'-amplification reagents for the IVT labeling kit (Affymetrix), and hybridized to a GeneChip Human Genome U133A Plus 2.0 array (Affymetrix) harboring $>45,000$ human probe sets. Hybridization, washing and detection of signals on the arrays were performed using the GeneChip System (Affymetrix), according to standard protocols provided by the manufacturer. The fluorescence intensity for each gene was normalized, based on the median expression value of the positive control genes (Affymetrix; HGU133Anorm.MSK) in each hybridization. Every microarray analysis was repeated twice. Hierarchical clustering of the data set was conducted using the Gene Spring software version 7.2 (Aglilent Technologies, Palo Alto, CA, USA). Statistical analysis was performed using the Student's t-test.

\section{Results}

Blood monocytes become macrophages in response to GM$C S F$ and $I L-3$. We analyzed the expression of GM-CSFR $\alpha$ and IL-3R $\alpha$ on peripheral blood $\mathrm{CD}_{1} 4^{+}$monocytes (Fig. 1). Monocytes displayed high and moderate levels of GM-CSFR $\alpha$ 


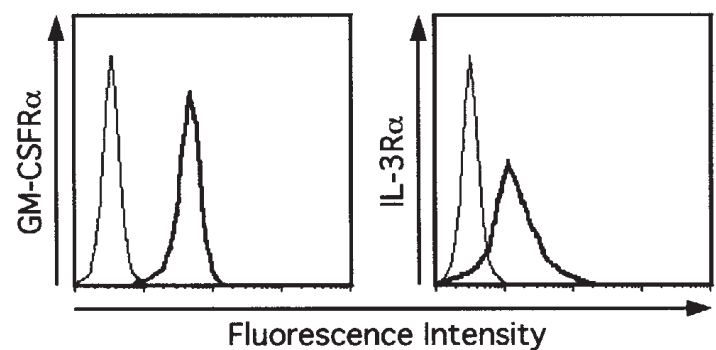

Figure 1. Cell surface expression of GM-CSFR $\alpha$ and IL-3R $\alpha$ on monocytes. $\mathrm{CD} 14^{+}$monocytes were stained with anti-GM-CSFR $\alpha$-FITC and anti-IL-3R $\alpha-$ PE. Fluorescence was analyzed using a FACSCalibur flow cytometer. The thick and thin lines represent the expression of the indicated molecules and isotype controls, respectively. Similar results were obtained with 3 different donors.

\section{GM-CSF}

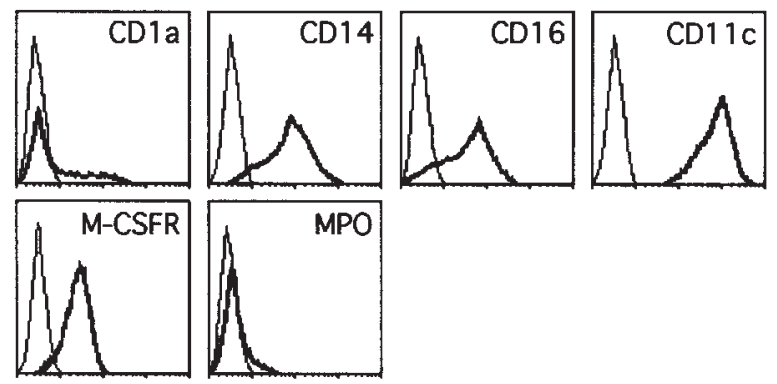

\section{$\mathrm{IL}-3$}
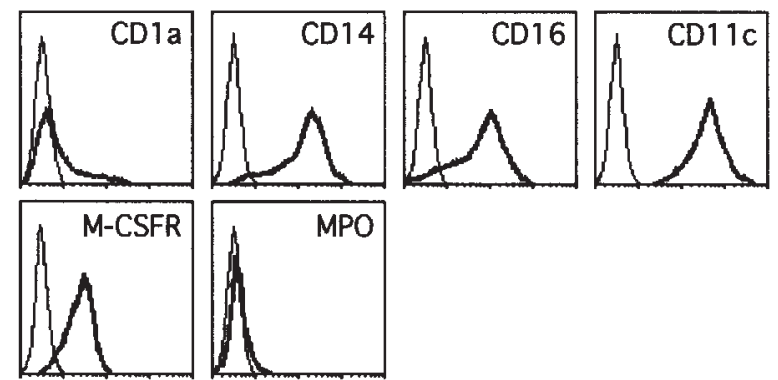

Figure 2. Phenotype of CD14+ monocytes cultured in the presence of GM-CSF or IL-3. CD14+ monocytes $\left(5 \times 10^{5} / \mathrm{ml}\right)$ were cultured for 7 days. The expression of CD1a, CD14, CD16, CD11c, M-CSFR and MPO was analyzed using a FACSCalibur flow cytometer. The thick and thin lines represent the expression of the indicated molecules and isotype controls, respectively. Similar results were obtained with 3 different donors.

and IL-3R $\alpha$, respectively, on their cell surface, consistent with previous reports $(7,18)$. We cultured $\mathrm{CD} 14^{+}$monocytes in the presence of GM-CSF and then evaluated the phenotype of the cultured cells on day 7 of incubation (Fig. 2). The cultured cells were positive for CD14, CD16, CD11c and M-CSFR but negative for CD1a and MPO. Culture of CD14+ monocytes with IL-3 also gave rise to cells with the phenotypic feature of $\mathrm{CD}_{1} \mathrm{a}^{-}, \mathrm{CD} 14^{+}, \mathrm{CD} 16^{+}, \mathrm{CD} 11 \mathrm{c}^{+}, \mathrm{M}_{-} \mathrm{CSFR}^{+}$ and MPO- The expression levels of CD14, CD16, CD11c and M-CSFR are very similar between the cells cultured with GM-CSF and those with IL-3. The resulting cells are indistinguishable between GM-CSF-containing and IL-3containing cultures, in terms of phenotype.
$\mathrm{IL}-3+\mathrm{IL}-4$

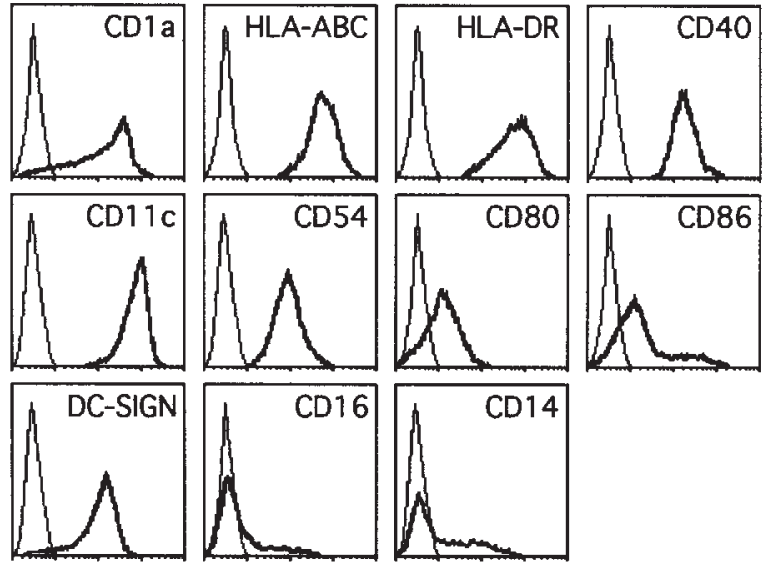

$\mathrm{GM}-\mathrm{CSF}+\mathrm{IL}-4$

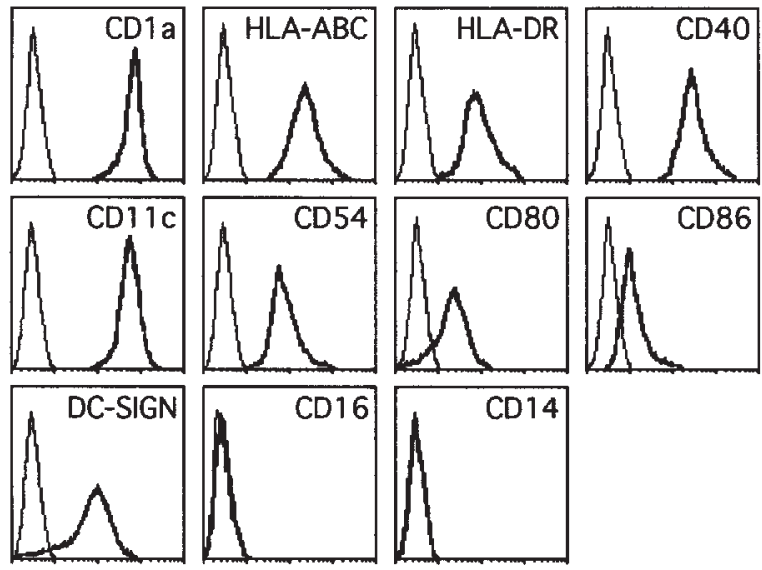

Figure 3. Phenotype of $\mathrm{CD} 14^{+}$monocytes cultured in the presence of IL-3 + IL-4 or GM-CSF + IL-4. CD14+ monocytes $\left(5 \times 10^{5} / \mathrm{ml}\right)$ were cultured for 7 days. The expression of CD1a, HLA-ABC, HLA-DR, CD40, CD11c, CD54, CD80, CD86, DC-SIGN, CD16 and CD14 was analyzed using a FACSCalibur flow cytometer. The thick and thin lines represent the expression of the indicated molecules and isotype controls, respectively. Similar results were obtained with 3 different donors.

Both GM-CSF and IL-3 induce the differentiation of blood monocytes into DCs in cooperation with $I L-4$. We next examined whether IL-3 as well as GM-CSF induce CD14+ monocytes to differentiate into DCs in the presence of IL-4. When the phenotype of CD14+ cells cultured with IL-3 plus IL-4 was analyzed on day 7 of incubation, the cells displayed high levels of CD1a, HLA-ABC, HLA-DR, CD40 and CD11c. They expressed CD54, CD80, CD86, and DC-SIGN but did not bear CD16 or CD14 (Fig. 3). These profiles are consistent with those of DCs generated from CD14+ cells with GM-CSF plus IL-4 as a comparison, although a small difference was observed in the expression level of $\mathrm{CD} 1 \mathrm{a}$, in accordance with a previous report (18). These data indicate that GM-CSF and IL-3 thus exert virtually similar activities on blood monocytes in the differentiation pathway toward DCs as well as macrophages.

GM-CSF but not IL-3 induces the differentiation of blood monocytes into Langerhans cells in the presence of TGF- $\beta 1$ 
GM-CSF + TGF- $\beta 1+$ Delta-1

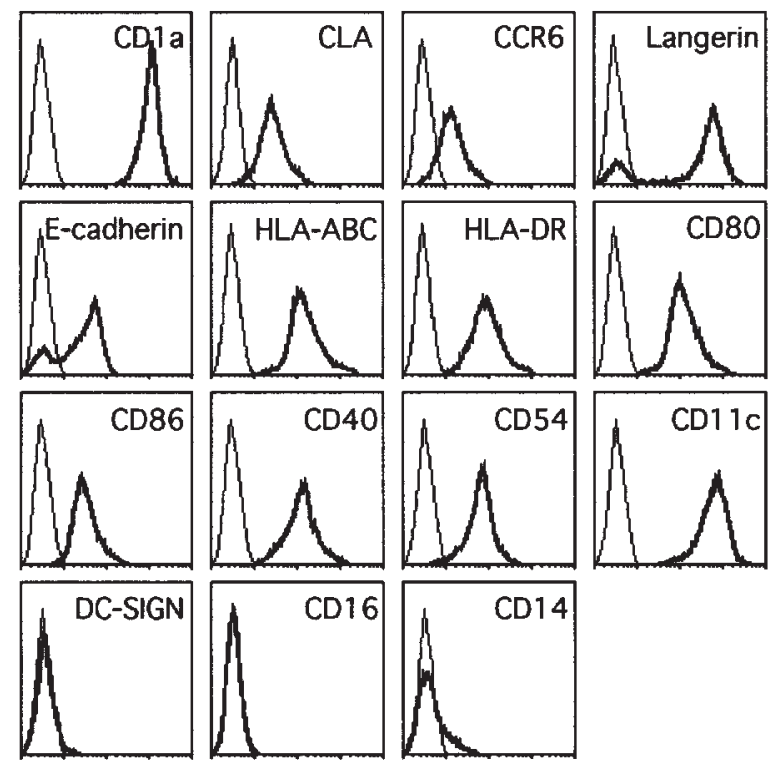

GM-CSF + IL-3 + TGF- $\beta 1$ + Delta-1

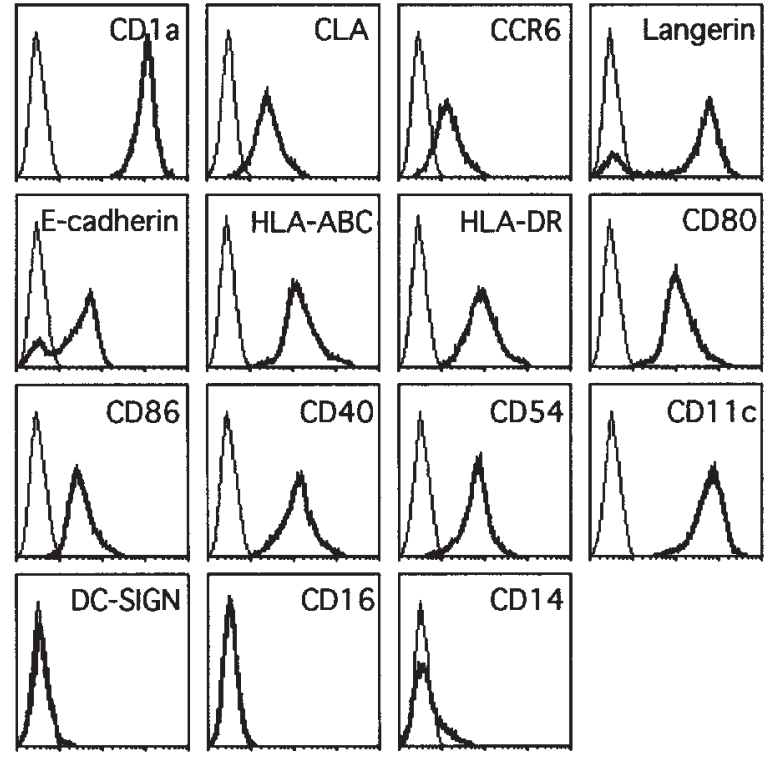

Figure 4. Phenotype of $\mathrm{CD}_{14} 4^{+}$monocytes cultured in the presence of GM-CSF + TGF- 31 + Delta-1, IL-3 + TGF- 11 + Delta-1 or GM-CSF + IL-3 + TGF- $\beta 1+$ Delta- 1 . CD $14^{+}$monocytes $\left(5 \times 10^{5} / \mathrm{ml}\right)$ were cultured for 7 days. The expression of CD1a, CLA, CCR6, Langerin, E-cadherin, HLA-ABC, HLA-DR, CD80, CD86, CD40, CD54, CD11c, DC-SIGN, CD16 and CD14 was analyzed using a FACSCalibur flow cytometer. The thick and thin lines represent the expression of the indicated molecules and isotype controls, respectively. Similar results were obtained with 3 different donors.

and Delta-1. Our recent study reported that GM-CSF, in concert with TGF- $\$ 1$ and Delta-1, promotes the differentiation of monocytes into Langerhans cells, as characterized by the expression of CLA, CCR6, Langerin and E-cadherin (13). They also express CD1a, HLA-ABC, HLA-DR, CD80, CD86, CD40, CD54 and CD11c. We, therefore, investigated whether monocytes differentiate into Langerhans cells in the presence of IL-3, TGF- 31 and Delta-1 instead of GM-CSF, TGF- 31 and Delta-1 (Fig. 4). In contrast to CD14+ monocytes cultured in the presence of GM-CSF, TGF- 11 and Delta-1, the cells

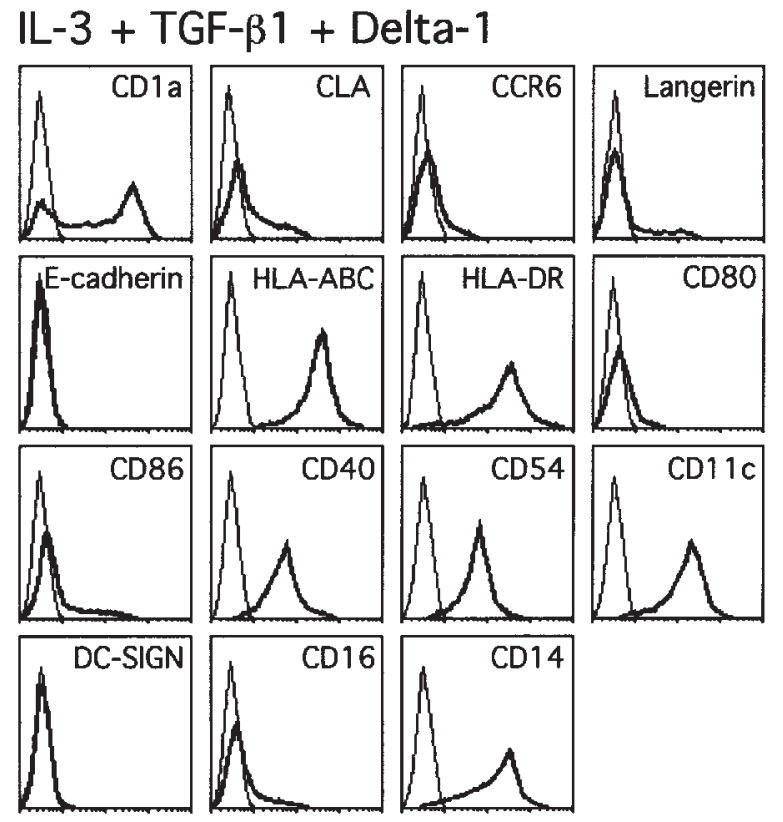

obtained from culture with IL-3, TGF- $\$ 1$ and Delta- 1 were negative for CLA, CCR6, Langerin and E-cadherin. These cells retained HLA-ABC, HLA-DR, CD40, CD54 and CD11c, while remaining negative for DC-SIGN. The expression level of CD1a, CD80 and CD86 declined, while CD14 was expressed. Therefore, IL-3 and GM-CSF most likely have a distinct effect on monocytes in the presence of TGF- 11 and Delta-1. We next added both GM-CSF and IL-3 to the cultures supplemented with TGF- $\beta 1$ and Delta-1. The cultured cells exhibited a phenotype similar to that observed with cultures containing GM-CSF, TGF-ß1 and Delta-1.

Gene expression profiles of $\mathrm{CD} 14^{+}$monocytes cultured with GM-CSF, TGF- $\beta 1$ and Delta-1 or with IL-3, TGF- $\beta 1$ and Delta-1. The cells generated from $\mathrm{CD} 14^{+}$monocytes with IL-3, TGF- 31 and Delta-1 appear to be phenotypically distinctive from those with GM-CSF, TGF- 31 and Delta-1. In an attempt to distinguish between these two cell groups, we performed gene expression profiling. To facilitate comparison of each group, we analyzed the 6 expression data sets of the cells cultured with GM-CSF, TGF- $\beta 1$ and Delta- $1(n=2)$, those with IL-3, TGF- 31 and Delta- $1(\mathrm{n}=2)$ and freshly isolated CD14+ monocytes $(n=2)$ (Fig. 5) and identified the genes which were differentially expressed between the former 2 groups. We first searched for the genes with expression levels more than 100 times higher in the cells cultured with GM-CSF, TGF- $B 1$ and Delta-1 than those cultured with IL-3, TGF- $\beta 1$ and Delta- 1 . Table I shows the genes whose expression was significantly different in the 2 groups (Student's t-test, $\mathrm{P}<0.05$ ). The well-known cell surface antigens for Langerhans cells, E-cadherin (gene symbol CDH1; GenBank accession no. NM 004360) and Langerin (gene symbol CD207; GenBank accession no. NM 015717), were abundantly expressed in the cells cultured with GM-CSF, TGF- 31 and Delta- 1 . In contrast, we did not detect the genes that were expressed more than 100-fold in cells cultured with IL-3, TGF-31 and Delta-1, in comparison to the cells cultured with GM-CSF, 


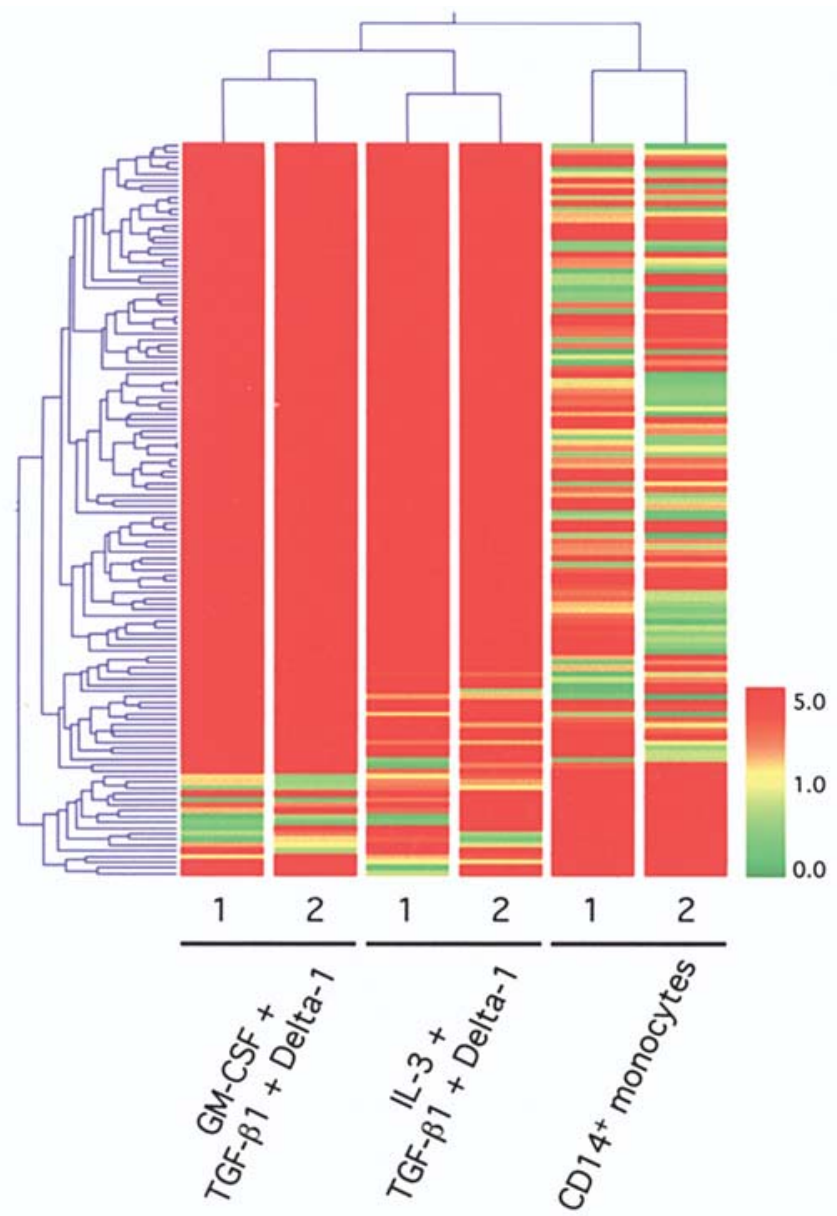

Figure 5. Expression profiles of genes specific for the cells cultured with GM-CSF + TGF-ß1 + Delta-1, for those with IL-3 + TGF-ß1 + Delta-1 and for freshly isolated $\mathrm{CD} 14^{+}$monocytes. The gene tree was constructed using 2-way clustering analysis of the genes whose expression is different among cells cultured with GM-CSF + TGF- 31 + Delta-1, those with IL-3 + TGF- 11 + Delta- 1 and freshly isolated $\mathrm{CD} 14^{+}$monocytes. Each row indicates a single gene on the microarray, and each column indicates a separate donor sample. The expression intensity of each gene is color-coded, according to the scale at the bottom right.

TGF- 11 and Delta-1. These data support the notion that IL-3 and GM-CSF act on monocytes in a different manner in the presence of TGF-ß1 and Delta-1.

\section{Discussion}

The receptor complexes for GM-CSF and IL-3 consist of a cytokine-specific $\alpha$ subunit and a $\beta c$ subunit (5). The $ß \mathrm{c}$ subunit is important for signal transduction. Our objective in this study was to determine whether IL-3 could function in the same manner as GM-CSF for the generation of Langerhans cells from $\mathrm{CD} 14^{+}$peripheral blood monocytes in the presence of TGF- 11 and Notch ligand Delta-1. Our data show that IL-3 did not induce Langerhans development from blood monocytes. This finding indicates that GM-CSF is essential for the development of Langerhans cells from human blood monocytes. The GM-CSF-specific $\alpha$ subunit may deliver the signals to monocytes for their Langerhans cell development. This notion is supported by our observation that the further addition of GM-CSF to the cultures containing IL-3, TGF- 31
Table I. Genes with a statistically high expression in cells cultured with GM-CSF + TGF- 1 1 + Delta-1.

\begin{tabular}{llccc}
\hline $\begin{array}{l}\text { Gene } \\
\text { symbol }\end{array}$ & $\begin{array}{c}\text { GenBank } \\
\text { accession } \\
\text { no. }\end{array}$ & $\begin{array}{c}\text { GM-CSF } \\
\text { + TGF-B1 } \\
\text { + Delta-1 }\end{array}$ & $\begin{array}{c}\text { IL-3 } \\
\text { + TGF-B1 } \\
\text { + Delta-1 }\end{array}$ & P-value \\
\hline LGR7 & NM_021634 & 699.7 & 6.7 & 0.049 \\
CDH1 & NM_004360 & 697.9 & 1.1 & 0.0341 \\
CLDN1 & AF101051 & 3851.3 & 80.3 & 0.0247 \\
LGR7 & AI805323 & 777.5 & 0.3 & 0.0235 \\
CCL17 & NM_002987 & 1028.5 & 6.6 & 0.0171 \\
HLA-DQB2 & X87344 & 6129.7 & 32.5 & 0.0157 \\
FCGBP & NM_003890 & 3813.8 & 45.9 & 0.013 \\
LGR7 & AI089319 & 791.6 & 1.5 & 0.00488 \\
CLDN1 & NM_021101 & 1158.5 & 1.9 & 0.0028 \\
CD207 & NM_015717 & 7854.7 & 24.6 & 0.00147 \\
\hline
\end{tabular}

and Delta-1 allowed monocytes to differentiate into Langerhans cells. Previous studies reported that none of the GM-CSF null and GM-CSF receptor $\beta$ chain null mice lacked epidermal Langerhans cells $(19,20)$. This demonstrates that GM-CSF does not have a selective effect on the development of Langerhans cells in vivo in mice. GM-CSF may be differentially required for Langerhans cell development between mice and humans. Inconsistent with our present study, Caux et al (21) reported that in cooperation with TNF- $\alpha$, IL-3 is similarly potent in generating dendric Langerhans cells from human cord blood $\mathrm{CD} 34^{+}$hematopoietic progenitor in comparison to GM-CSF. It is likely that the common $B$ chain-mediated signals elicited by GM-CSF or IL-3 play a pivotal role in the development of Langerhans cells from hematopoietic progenitor cells but not from blood monocytes.

It is generally accepted that GM-CSF and IL-3 induce the differentiation of monocytes into macrophages. As expected, our data obtained from a phenotypic analysis also supported this idea. When monocytes were cultured with GM-CSF or IL-3 in the presence of IL-4, the resulting cells from both cultures exhibited the phenotype of DCs with the minor exception of the expression pattern of CD1a. These findings suggest that the signals mediated through the $B c$ chain of GM-CSF and IL-3 receptors are mainly involved in the differentiation process of monocytes into macrophages and DCs, which may be different in the case of Langerhans cell development from monocytes.

Interestingly, our microarray analysis indicated that although there existed a small subset of genes whose transcripts were significantly up-regulated in the cells cultured with GM-CSF, TGF- 11 and Delta-1 in comparison to those with IL-3, TGF- 11 and Delta-1, there were no genes that were more than 100-fold up-regulated in the cells cultured with IL-3, TGF- 31 and Delta-1. It may be speculated that the cells obtained from cultures with IL-3, TGF- 31 and Delta-1 are intermediate between monocytes and Langerhans cells, in terms of their gene expression. It is also interesting to note that the subset of genes that were more abundantly expressed in the cells cultured with GM-CSF, TGF- $\beta 1$ and Delta-1 
included E-cadherin and Langerin which are Langerhans cell markers. In this context, it is relevant that the signals mediated through the GM-CSF-specific $\alpha$ chain are indispensable for the induction of Langerhans cells from monocytes. Consequently, we considered that it would be interesting to examine whether or not a selective block of the GM-CSF receptor $\alpha$ chain suppresses the differentiation of monocytes into Langerhans cells in the presence of GM-CSF, IL-3, TGF-ß1 and Delta-1. However, even though we used several anti-GM-CSF receptor $\alpha$ chain neutralizing mAbs, they failed to inhibit the Langerhans cell development from monocytes (data not shown). At present, no likely explanation can be provided for this failure. Further studies are required to address this issue.

An earlier study has shown that human cord blood CD34+ hematopoietic progenitor cells generate CD14- precursors which give rise to Langerhans cells (22). We observed that $\mathrm{CD} 14^{+}$monocytes which are derived from CD $34^{+}$hematopoietic progenitor cells differentiate into Langerhans cells, in agreement with previous reports that demonstrate the generation of Langerhans cells from CD14+ blood monocytes $(23,24)$. These results may therefore represent two distinct differentiation pathways from $\mathrm{CD} 34^{+}$hematopoietic progenitor cells toward Langerhans cells.

GM-CSF and TGF- $\beta 1$ are produced by keratinocytes (25-27). Delta-1 is expressed by epidermal stem cells which are surrounded by keratinocytes (28). The constitutive expression of IL-3 is not detected in normal cells. The cellular source of IL-3 is restricted to activated T cells $(29,30)$. Together with these findings, our data emphasize the importance of the skin cytokine environment in the development of Langerhans cells from blood monocytes.

\section{Acknowledgements}

We thank Brian Quinn (Kyushu University, Fukuoka, Japan) for critical comments and language assistance.

\section{References}

1. Sieff CA: Hematopoietic growth factors. J Clin Invest 79: 1549-1557, 1987.

2. Moore MAS: Clinical implications of positive and negative hematopoietic stem cell regulators. Blood 78: 1-19, 1991.

3. Metcalf D: Hematopoietic regulators: redundancy or subtlety? Blood 82: 3515-3523, 1993.

4. Ogawa M: Differentiation and proliferation of hematopoietic stem cells. Blood 81: 2844-2853, 1993.

5. Miyajima A, Mui A L-F, Ogorochi T and Sakamaki K: Receptors for granulocyte-macrophage colony-stimulating factor, interleukin-3, and interleukin-5. Blood 82: 1960-1974, 1993.

6. Wiktor-Jedrzejczak W and Gordon S: Cytokine regulation of the macrophage $(\mathrm{M} \phi)$ system studied using the colony stimulating factor-1-deficient op/op mouse. Physiol Rev 76: 927-947, 1996.

7. Rissoan M-C, Soumelis V, Kadowaki N, Grouard G, Briere F, De Waal Malefyt R and Liu Y-J: Reciprocal control of T helper cell and dendritic cell differentiation. Science 283: 1183-1186, 1999.

8. Armitage JO: Emerging applications of recombinant human granulocyte-macrophage colony-stimulating factor. Blood 92: 4491-4508, 1998

9. Sallusto F and Lanzavecchia A: Efficient presentation of soluble antigen by cultured human dendritic cells is maintained by granulocyte/macrophage colony-stimulating factor plus interleukin 4 and downregulated by tumor necrosis factor $\alpha$. J Exp Med 179: 1109-1118, 1994.
10. Romani N, Gruner S, Brang D, Kampgen E, Lenz A, Trockenbacher B, Konwalinka G, Fritsch PO, Steinman RM and Schuler G: Proliferating dendritic cell progenitors in human blood. J Exp Med 180: 83-93, 1994.

11. Zhou LJ and Tedder TF: CD14 ${ }^{+}$blood monocytes can differentiate into functionally mature CD83 ${ }^{+}$dendritic cells. Proc Natl Acad Sci USA 93: 2588-2592, 1996.

12. Ebner S, Hofer S, Nguyen VA, Furhapter C, Herold M, Fritsch P, Heufler C and Romani N: A novel role for IL-3: human monocytes cultured in the presence of IL-3 and IL-4 differentiate into dendritic cells that produce less IL-12 and shift Th cell responses toward a Th2 cytokine pattern. J Immunol 168: 6199-6207, 2002.

13. Hoshino N, Katayama N, Shibasaki T, Ohishi K, Nishioka J, Masuya M, Miyahara Y, Hayashida M, Shimomura D, Kato T, Nakatani K, Nishii K, Kuribayashi K, Nobori T and Shiku H: A novel role for Notch ligand Delta-1 as a regulator of human Langerhans cell development from blood monocytes. J Leukoc Biol 78: 921-929, 2005

14. Varnum-Finney B, Purton LE, Yu M, Brashem-Stein C, Flowers D, Staats S, Moore KA, Le Roux I, Mann R, Gray G, Artavanis-Tsakonas S and Bernstein ID: The Notch ligand, Jagged-1, influences the development of primitive hematopoietic precursor cells. Blood 91: 4084-4091, 1998.

15. Ohishi K, Varnum-Finney B, Flowers D, Anasetti C, Myerson D and Bernstein ID: Monocytes express high amounts of Notch and undergo cytokine specific apoptosis following interaction with the Notch ligand, Delta-1. Blood 95: 2847-2854, 2000

16. Ohmine K, Ota J, Ueda M, Ueno S, Yoshida K, Yamashita Y, Kirito K, Imagawa S, Nakamura Y, Saito K, Akutsu M, Mitani K, Kano Y, Komatsu N, Ozawa K and Mano H: Characterization of stage progression in chronic myeloid leukemia by DNA microarray with purified hematopoietic stem cells. Oncogene 20: 8249-8257, 2001

17. Makishima H, Ishida F, Ito $T$, Kitano $K$, Ueno S, Ohmine $K$, Yamashita Y, Ota J, Ota M, Yamauchi K and Mano H: DNA microarray analysis of $\mathrm{T}$ cell-type lymphoproliferative disease of granular lymphocytes. Br J Haematol 118: 462-469, 2002.

18. Buelens C, Bartholome EJ, Amraoui Z, Boutriaux M, Salmon I, Thielemans K, Willems F and Goldman M: Interleukin-3 and interferon $B$ cooperate to induce differentiation of monocytes into dendritic cells with potent helper T-cell stimulatory properties. Blood 99: 993-998, 2002.

19. Vremec D, Lieschke GJ, Dunn AR, Robb L, Metcalf D and Shortman K: The influence of granulocyte/macrophage colonystimulating factor on dendritic cell levels in mouse lymphoid organs. Eur J Immunol 27: 40-44, 1997.

20. Burnham K, Robb L, Scott CL, O'Keeffe M and Shortman K: Effect of granulocyte-macrophage colony-stimulating factor on the generation of epidermal Langerhans cells. J Interferon Cytokine Res: 20: 1071-1076, 2000.

21. Caux C, Vanbervliet B, Massacrier C, Durand I and Banchereau J: Interleukin-3 cooperates with tumor necrosis factor $\alpha$ for the development of human dendritic/Langerhans cells from cord blood $\mathrm{CD} 4^{+}$hematopoietic progenitor cells. Blood 87: 2376-2385, 1996.

22. Caux C, Vanbervliet B, Massacrier C, Dezutter-Dambuyant C, De Saint-Vis B, Jacquet C, Yoneda K, Imamura S, Schmitt D and Banchereau $\mathrm{J}$ : $\mathrm{CD} 34^{+}$hematopoietic progenitors from human cord blood differentiate along two independent dendritic cell pathways in response to GM-CSF+TNF $\alpha$. J Exp Med 184: 695-706, 1996.

23. Geissmann F, Prost C, Monnet J-P, Dy M, Brousse N and Hermine O: Transforming growth factor $B 1$, in the presence of granulocyte/macrophage colony-stimulating factor and interleukin 4 , induces differentiation of human peripheral blood monocytes into dendritic Langerhans cells. J Exp Med 187: 961-966, 1998.

24. Mohamadzadeh M, Berard F, Essert G, Chalouni C, Pulendran B, Davoust J, Bridges G, Palucka AK and Banchereau J: Interleukin 15 skews monocyte differentiation into dendritic cells with features of Langerhans cells. J Exp Med 194: 1013-1019, 2001.

25. Gasson JC: Molecular physiology of granulocyte-macrophage colony-stimulating factor. Blood 77: 1131-1145, 1991.

26. Sporn $M B$ and Roberts $A B$ : Transforming growth factor- $B$ : recent progress and new challenges. J Cell Biol 119: 1017-1021, 1992. 
27. Pastore S, Fanales-Belasio E, Albanesi C, Chinni LM, Giannetti A and Girolomoni G: Granulocyte macrophage colony-stimulating factor is overproduced by keratinocytes in atopic dermatitis: implications for sustained dendritic cell activation in the skin. J Clin Invest 99: 3009-3017, 1997.

28. Lowell S, Jones P, Le Roux I, Dunne J and Watt FM: Stimulation of human epidermal differentiation by delta-notch signaling at the boundaries of stem-cell clusters. Curr Biol 10: 491-500, 2000.
29. Otsuka T, Miyajima A, Brown N, Otsu K, Abrams J, Saeland S, Caux C, De Waal Malefijt R, De Vries J, Meyerson P, Yokota K, Gemmel L, Rennick D, Lee F, Arai N, Arai K and Yokota T: Isolation and characterization of an expressible cDNA encoding human IL-3: induction of IL-3 mRNA in human T cell clones. J Immunol 140: 2288-2295, 1988.

30. Niemeyer CM, Sieff CA, Mathey-Prevot B, Wimperis JZ, Bierer BE, Clark SC and Nathan DG: Expression of human interleukin-3 (multi-CSF) is restricted to human lymphocytes and T-cell tumor lines. Blood 73: 945-951, 1989. 